\title{
Crocetin Downregulates the Proinflammatory Cytokines in Methylcholanthrene-Induced Rodent Tumor Model and Inhibits COX-2 Expression in Cervical Cancer Cells
}

\author{
Bing Chen, Zhao-Hui Hou, Zhe Dong, and Chun-Dong Li \\ Department of Obstetrics and Gynaecology, Air Force General Hospital, PLA, Beijing 100142, China \\ Correspondence should be addressed to Chun-Dong Li; chundongli@tom.com
}

Received 9 August 2014; Accepted 11 September 2014

Academic Editor: John E. Smith

Copyright (c) 2015 Bing Chen et al. This is an open access article distributed under the Creative Commons Attribution License, which permits unrestricted use, distribution, and reproduction in any medium, provided the original work is properly cited.

\begin{abstract}
The effect of crocetin $\left(\mathrm{C}_{20} \mathrm{H}_{24} \mathrm{O}_{4}\right)$ on methylcholanthrene- (MCA-) induced uterine cervical cancer in mice was studied in this paper. After the mice were treated orally with crocetin, maleic dialdehyde (MDA), polymorphonuclear cells (PMN), interleukin$1 \beta$ (IL-1 $\beta)$, and tumor necrosis factor- $\alpha$ (TNF- $\alpha$ ) were examined by ELISA or immunohistochemistry. The inducible nitric oxide synthase (iNOS) activation in HeLa cells was analyzed using fluorescence microscopy for light microscopic examination. The MCA mice showed a significant increase in plasma MDA, PMN, IL- $1 \beta$, TNF- $\alpha$, and nitrates levels. At the same time, the mRNA level of COX-2 in HeLa cells was also significantly increased. These changes were attenuated by crocetin supplementation in the MCA mice. Crocetin supplementation in the MCA mice also showed protection against cervical cancer. These results suggest that crocetin may act as a chemopreventive and an anti-inflammatory agent.
\end{abstract}

\section{Introduction}

Cervical cancer is the second most common cancer in women worldwide [1]. Despite improved knowledge of the etiology of cervical cancer, aggressive cytoreductive surgery, and modern combination chemotherapy, there has been little change in the mortality statistics over the last 30 years. Compelling evidence has shown that the majority of cancers arise from sites of chronic irritation, infection, and inflammation, solidifying the concept that chronic unabated inflammation is critical for tumour progression [2]. The microenvironment of the tumor highly resembles an inflammation site which results from enhancement of the levels of cytokines, chemokines, neutrophils, eosinophils, mast cells, lymphocytes, and macrophages both in the surrounding stroma and within the neoplasm itself [3]. Recent clinical trials have shown that long-term anti-inflammatory treatment can be beneficial in colorectal cancer [4]. So the pharmacological agents effective for the treatment of inflammatory diseases may also be employed in cervical cancer.

Crocetin $\left(\mathrm{C}_{20} \mathrm{H}_{24} \mathrm{O}_{4}\right)$ is one of the major active constituents of saffron, which is derived from the dried stigma of Crocus sativus L., and belongs to the Iridaceae family. Previous studies have demonstrated various pharmacological effects of this active constituent including its antioxidant, anti-inflammatory, and antitumor effects on some cell lines and animal models of cancer [4-8]. However, nothing is known about effects of crocetin in the uterine cervix tumorigenesis. In the present study, we investigated its anti-inflammatory effect on the interleukin-1 $\beta$ (IL-1 $\beta$ ), tumor necrosis factor- $\alpha$ (TNF- $\alpha$ ), and PMNs activity in a methylcholanthrene- (MCA-) induced uterine cervix tumorigenesis murine model system. Further, the effects of crocetin on expression of cyclooxygenase-2 (COX-2) in HeLa cells were also evaluated.

\section{Material and Methods}

2.1. Drugs. Methylcholanthrene (MCA) was purchased from Sigma Co., Ltd. Crocetin was purchased from Yiji Natural Products Co., Ltd., China.

2.2. Animals. This study was performed in accordance with the Guide for the Care and Use of Laboratory Animals. Care 
was taken to minimize discomfort, distress, and pain of the animals.

2.3. Experimental Design. Female Kunming strain mice weighing 20-22 g were maintained at room temperature under alternating natural light/dark photoperiod and had access to standard laboratory food and fresh water ad libitum. Murphy's string method [9] was followed for the induction of tumors in the uterine cervix of mice. Briefly, sterile double cotton thread impregnated with beeswax containing $600 \mu \mathrm{g}$ of MCA was inserted into the canal of the uterine cervix by means of laparotomy under mild ether anaesthesia. Fortyeight of these mice were allocated equally into 4 groups: MCA-induced group, MCA and Crocetin-10 group, MCA and Crocetin-20 group, and MCA and Crocetin-40 group. The other 12 normal mice were used as the control group. From then on, the 5 groups of mice were administered orally saline, Crocetin $10 \mathrm{mg} / \mathrm{kg}$, Crocetin $20 \mathrm{mg} / \mathrm{kg}$, Crocetin $40 \mathrm{mg} / \mathrm{kg}$, and saline, respectively. Crocetin was dissolved in distilled water and administrated orally twice daily using a feeding needle for 35 days, and control group received double distilled water instead of crocetin.

At the end of the experimental period, the animals were fasted overnight $(18 \mathrm{~h})$ and then sacrificed by decapitation, the blood was collected to be centrifuged at $3000 \mathrm{rpm}$ for $20 \mathrm{~min}$, and the clear serum was separated for the measurement of inflammatory cells and inflammatory mediators. The tumor volumes and iNOS protein histochemistry were determined.

2.4. Measurement of Maleic Dialdehyde (MDA). MDA was determined with thiobarbituric acid (TBA) using the manufacturer's instructions (Nanjing Jiancheng Bioengineering Institute). Total protein content of the samples was analyzed using Coomassie blue assay (Nanjing Jiancheng Bioengineering Institute).

2.5. Measurement of Infiltration of PMN. Myeloperoxidase (MPO) activity was measured to assess the extent of PMN infiltration. The method of assaying MPO activity was according to the guide of the assay kit (Nanjing Jiancheng Bioengineering Co. Ltd., China).

2.6. Measurement of $I L-1 \beta$ and TNF- $\alpha$ Level. The concentration of IL- $1 \beta$ and TNF- $\alpha$ was determined using a commercial ELISA kit (Shanghai Jinma Biological Technology, Inc., China) following the manufacturer's instruction.

2.7. Assessment of iNOS Protein Histochemistry. The tumors were dissected free from soft tissues at the end of the study and collected on chrome gel subbed slides. Tissue sections were fixed in $50 \%$ acetone in phosphate-buffered saline for 3 minutes at room temperature and endogenous peroxidase activity was blocked by $1.5 \% \mathrm{H}_{2} \mathrm{O}_{2}$ in methanol for 15 minutes. The iNOS protein was determined using a commercial ELISA kit (Shanghai Jinma Biological Technology, Inc., China) following the manufacturer's instruction.
2.8. Cell Culture. HeLa cells (human cervical cancer HeLa cell line was obtained from Cell Culture Center of Shanghai Science Academy, China) were maintained in Petri dishes at $37^{\circ} \mathrm{C}$ in a Dulbecco-modified Eagle culture medium supplemented with $10 \%$ fetal calf serum and $1 \%$ antibiotic mixture, under a humidified atmosphere containing 5\% carbon dioxide. The culture medium was changed twice per week. After they had reached their growth plateau, the cells were used for inoculation by mechanical harvest and transfer to fresh culture medium.

2.9. Crocetin Inhibited COX-2 Production in HeLa Cells. Analysis of COX-2 production was performed using an ELISA kit according to manufacturer's instructions (Shanghai Jinma Biological Technology, Inc., China). HeLa cells were treated with various concentrations of crocetin $(1,10,50$, and $100 \mu \mathrm{mol} / \mathrm{L})$ for $24 \mathrm{~h}$. Cell culture supernatants were collected to measure the concentration of COX-2. Production of COX2 was normalized to protein concentrations.

Total RNA was extracted from crocetin-treated and untreated HeLa cells using GenElute Mammalian Genomic Total RNA Isolation Kit (Sigma) as per the manufacturer's protocol. The extracted RNA samples were then subjected to reverse transcription- (RT-) PCR for analysis of expression of COX-2.

2.10. Statistical Analysis. The data were expressed as mean \pm SEM and results were analyzed by ANOVA followed by Dunnett's $t$ test. $P<0.05$ was considered significant.

\section{Results and Discussion}

A considerable body of evidence has supported the concept that tumors can originate at the sites of infection or chronic inflammation [10-12]. Many pathological disorders or diseases, including cervical cancer, are characterised by the exacerbated activation and maintenance of inflammatory pathways $[13,14]$. In the current study, we found that MCAinduced carcinogenesis in the mouse uterine cervix in animals results in significantly increased circulating concentrations of inflammatory cytokines and tumor necrosis factor- $\alpha$ (TNF- $\alpha$ ), when compared with controls. It is in agreement with previous data [10-14].

Peroxidation damage plays an important role in the progression of inflammation mediated diseases in particular cervical cancer. The central dogma in chronic inflammation hypothesis emphasizes the role of ROS generated by phagocytes, which cause cytotoxicity and mutagenesis [15-17]. Therefore, the antioxidant effects of crocetin were investigated by measuring MDA levels. The control animals showed low MDA levels; however, the MDA levels in the MCA group were significantly higher $(P<0.05)$. As shown in Figure 1, MDA levels in the crocetin $(40 \mathrm{mg} / \mathrm{kg})$ and crocetin $(20 \mathrm{mg} / \mathrm{kg})$ groups were significantly lower than those in the MCA group $(P<0.01$ and $P<0.05$, resp.). This result is in agreement with previous reports $[18,19]$. It suggests that crocetin might exert a profound effect on inhibition of lipid peroxidation and free radical generation. 


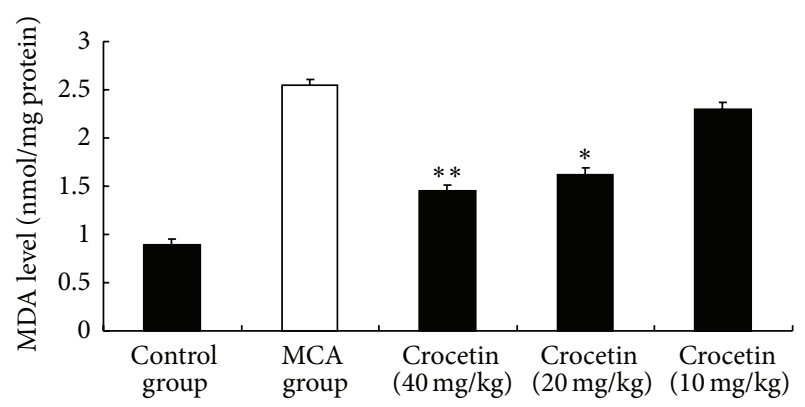

FIgURE 1: Effect of crocetin on MDA level. Values represent the mean \pm SEM. ${ }^{*} P<0.05$ versus MCA group. ${ }^{* *} P<0.01$ versus MCA group.

TABLE 1: Effects of crocetin on PMNs activities.

\begin{tabular}{lc}
\hline Different groups & $\left(\mu \mathrm{mol} \cdot \mathrm{g}^{-1}\right)$ \\
\hline Control & $0.99 \pm 0.20$ \\
MCA & $2.00 \pm 0.20$ \\
Crocetin $(40 \mathrm{mg} / \mathrm{kg})$ & $1.00 \pm 0.10^{*}$ \\
Crocetin $(20 \mathrm{mg} / \mathrm{kg})$ & $1.30 \pm 0.25$ \\
Crocetin $(10 \mathrm{mg} / \mathrm{kg})$ & $1.80 \pm 0.22$ \\
\hline
\end{tabular}

Values are shown as means \pm SEM. ${ }^{*} P<0.05$ versus MCA group.

The association between tumor cells and polymorphonuclear cells (PMNs) has been demonstrated in several types of cancer $[20,21]$. However, the role of PMNs in cervical cancer progression has not been well studied in vivo. In this study, the PMNs activity was relatively low in control group and significantly increased in the MCA group. Treatment with crocetin of $40 \mathrm{mg} / \mathrm{kg}$ significantly reduced PMNs activity (Table 1). Treatment with crocetin of $20 \mathrm{mg} / \mathrm{kg}$ reduced PMNs activity also. However, it is not significant. PMNs may contribute to secondary injury by causing microvessel occlusion and releasing oxygen radicals, cytolytic proteases, and proinflammatory cytokines, which may induce the neuronal damage $[22,23]$. In the present study, we observed a dosedependent inhibitory effect of crocetin on PMNs activity, indicating less neutrophil infiltration into the lesion site.

Key features of cancer-related inflammation include the infiltration of white blood cells and cytokines such as interleukin (IL)-1, IL-6, and tumor necrosis factor- $\alpha$ (TNF- $\alpha$ ) [24]. IL-1 $\beta$ has been shown to be upregulated in many cancers and confers chemoresistance in pancreatic carcinoma [25]. Our study is consistent with these studies. Figure 2 shows that MCA significantly increased protein concentration of IL$1 \beta$. Crocetin $(40 \mathrm{mg} / \mathrm{kg})$ and crocetin $(20 \mathrm{mg} / \mathrm{kg})$ treatment decreased the level of IL- $1 \beta$ by $34 \%$ and $56 \%$ as compared to the MCA group, respectively $(P<0.05)$. TNF- $\alpha$ is an inflammatory cytokine which may play important roles in the progression of cervical lesions [26]. TNF- $\alpha$ was measured in blood to evaluate whether the concentration of this cytokine was systemically influenced by crocetin. Furthermore, this helps elucidate whether or not TNF- $\alpha$ can be implicated in the effect that was seen on neutrophil migration. As shown in Figure 3, the levels of TNF- $\alpha$ elevated significantly after induction of tumors with MCA. Crocetin $(40 \mathrm{mg} / \mathrm{kg})$

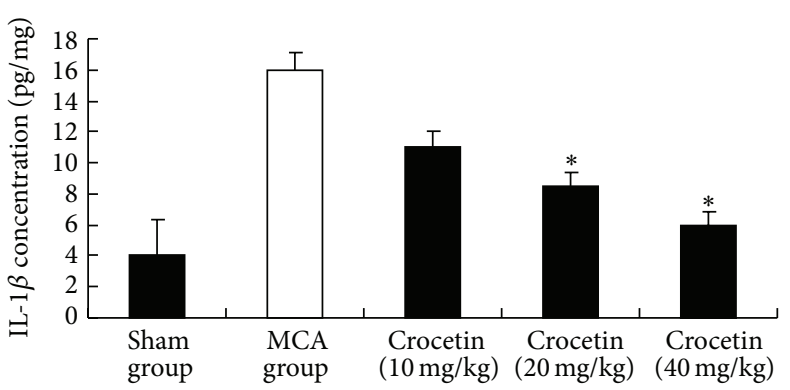

FIGURE 2: Effect of crocetin on IL-1 $\beta$ concentration. Values represent the mean \pm SEM. ${ }^{*} P<0.05$ versus MCA group.

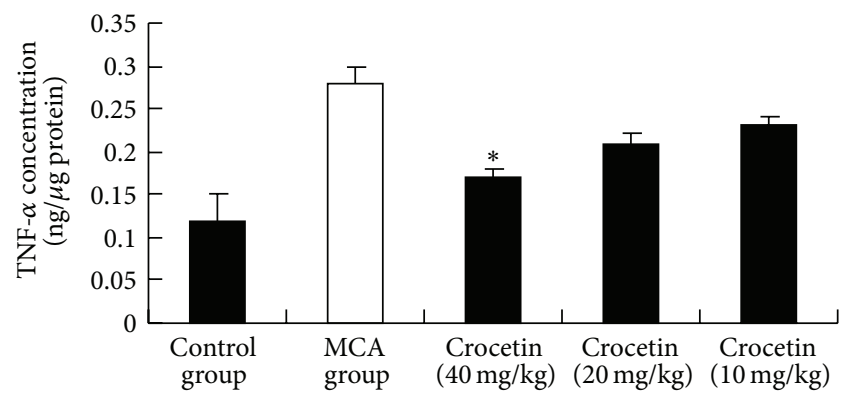

FIGURE 3: Effect of crocetin on TNF- $\alpha$ concentration. Values represent the mean \pm SEM. ${ }^{*} P<0.05$ versus MCA group.

TABLE 2: Effects of crocetin on tumor volumes.

\begin{tabular}{lc}
\hline Different groups & Tumor volume $\left(\mathrm{mm}^{3}\right)$ \\
\hline Control & 0 \\
MCA & $10.4 \pm 0.30$ \\
Crocetin $(40 \mathrm{mg} / \mathrm{kg})$ & $6.00 \pm 0.10^{*}$ \\
Crocetin $(20 \mathrm{mg} / \mathrm{kg})$ & $7.32 \pm 0.22$ \\
Crocetin $(10 \mathrm{mg} / \mathrm{kg})$ & $8.80 \pm 0.33$ \\
\hline
\end{tabular}

Values are shown as means \pm SEM. ${ }^{*} P<0.05$ versus MCA group.

suppressed this response $(P<0.05)$. We demonstrated in this study that administration of crocetin decreased serum levels of IL- $1 \beta$ and TNF- $\alpha$ that are known to be produced by induction of tumors with MCA. Results from studies on cytokines have given us some insight into the mechanisms involved in the protection of crocetin against cervical cancer (Table 2).

Inducible NOS is induced in response to inflammatorylike stimuli and is capable of sustained production of high levels of NO that predominate during inflammation [27]. The excessive or inappropriate production of $\mathrm{NO}$ can damage tissue through the superoxide anion $\left(\mathrm{O}_{2}{ }^{-}\right)$[28]. The fluorescence microscopy analyses showed evidence of widespread iNOS expression in tumor cells from animals with MCA but no evidence of iNOS immunoreactivity in controls. Treatment with crocetin $(40 \mathrm{mg} / \mathrm{kg})$ also inhibited the iNOS expression in bone marrow cells (Figure 4).

According to a previous research by Subbaramaiah and Dannenberg, COX-2 is involved in inflammation and its upregulation has been reported in various cancers [29]. In the 


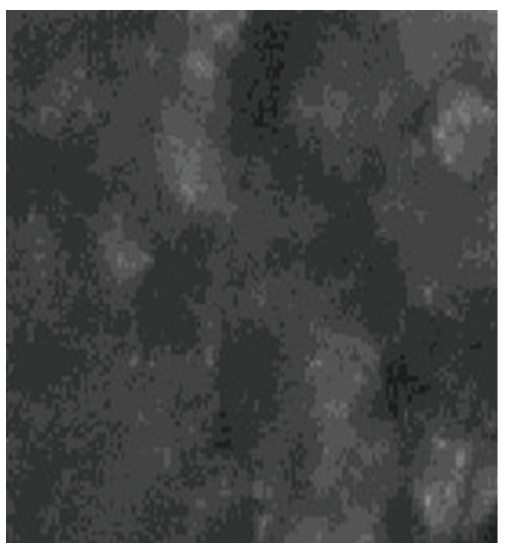

(a)

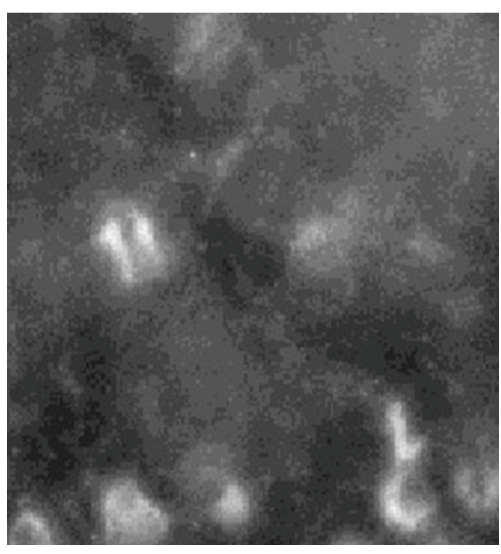

(b)

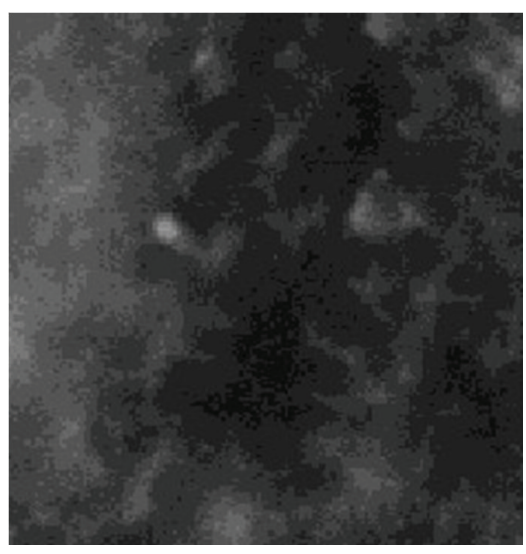

(c)

FIgURE 4: Demonstration of iNOS protein in tumor. All photographs were taken at an exposure time of $1 \mathrm{~s}$. Magnification $\times 400$. (a) iNOS in cytoplasm of tumor cells of control rat. (b) iNOS in cytoplasm of tumor cells of IMO rat. (c) iNOS in cytoplasm of tumor cells of crocetin $(40 \mathrm{mg} / \mathrm{kg})$ rat.

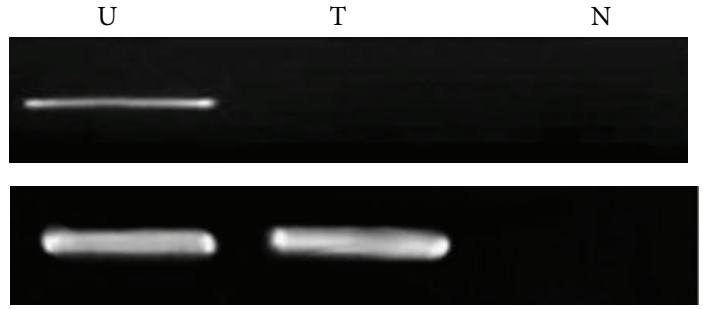

(a)

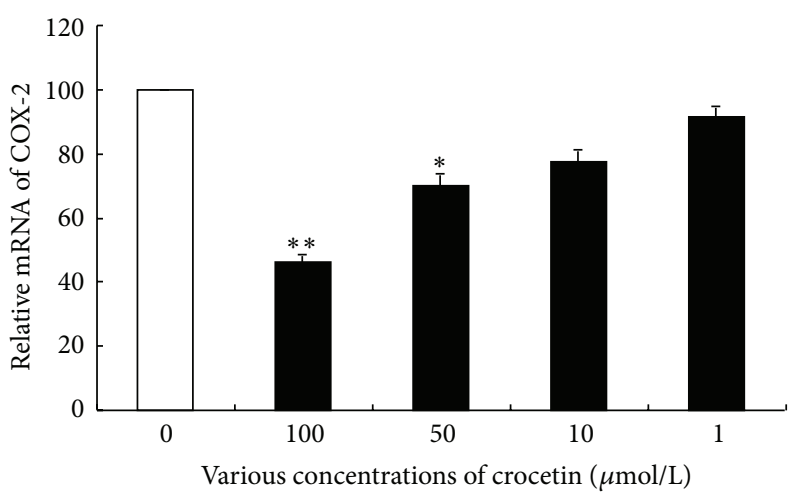

(b)

FIgure 5: Crocetin inhibited COX-2 production and expression in HeLa cells. (a) Expression analysis of COX-2 in HeLa cells. Lane U shows untreated HeLa cells; lane T shows crocetin-treated HeLa cells; lane $\mathrm{N}$ shows negative control for RT-PCR. $\beta$-Actin was used as an internal control. Representative gels from one of the three experiments were used. (b) The mRNA level of COX-2 was measured in HeLa cells treated with various concentrations of crocetin for $24 \mathrm{~h}$. Values represent the mean \pm SEM. ${ }^{*} P<0.05$ versus control group.

present study, HeLa cells were shown to express high levels of COX-2, which was subsequently downregulated on treatment with crocetin (Figure 5(a)). Relative to nontreated controls, crocetin dose-dependently decreased COX-2 production in cervical cancer cells (Figure 5(b)). It has been suggested that COX-2 is an important target for the chemopreventive effects of these agents. The present study is consistent with this study [30]. Our observations prompt us to suggest that inhibition of COX-2 production by crocetin may suppress growth and invasiveness of cervical carcinomas.

\section{Conclusion}

This study suggested for the first time that crocetin has an anti-inflammatory effect by suppressing the level of IL- $1 \beta$ and TNF- $\alpha$ as well as PMNs activity in a MCA-induced uterine cervix tumorigenesis murine model system. Further, crocetin dose-dependently decreased COX-2 production in cervical cancer cells. Overall, crocetin demonstrated potent in vitro and in vivo anti-inflammatory activities. It provided support for the potential of using crocetin as a chemopreventive and an anti-inflammatory agent.

\section{Conflict of Interests}

The authors declare that there is no conflict of interests.

\section{References}

[1] M. Arbyn, X. Castellsagué, S. de sanjosé et al., "Worldwide burden of cervical cancer in 2008," Annals of Oncology, vol. 22, no. 12, pp. 2675-2686, 2011.

[2] L. M. Coussens and Z. Werb, "Inflammation and cancer," Nature, vol. 420, no. 6917, pp. 860-867, 2002.

[3] C. Caruso, D. Lio, L. Cavallone, and C. Franceschi, "Aging, longevity, inflammation, and cancer," Annals of the New York Academy of Sciences, vol. 1028, pp. 1-13, 2004.

[4] T.-H. Tseng, C.-Y. Chu, J.-M. Huang, S.-J. Shiow, and C.J. Wang, "Crocetin protects against oxidative damage in rat 
primary hepatocytes," Cancer Letters, vol. 97, no. 1, pp. 61-67, 1995.

[5] A. Poma, G. Fontecchio, G. Carlucci, and G. Chichiriccò, "Antiinflammatory properties of drugs from saffron crocus," AntiInflammatory and Anti-Allergy Agents in Medicinal Chemistry, vol. 11, no. 1, pp. 37-51, 2012.

[6] A. Dhar, S. Mehta, G. Dhar et al., "Crocetin inhibits pancreatic cancer cell proliferation and tumor progression in a xenograft mouse model," Molecular Cancer Therapeutics, vol. 8, no. 2, pp. 315-323, 2009.

[7] V. Magesh, J. P. Vijeya Singh, K. Selvendiran, G. Ekambaram, and D. Sakthisekaran, "Antitumour activity of crocetin in accordance to tumor incidence, antioxidant status, drug metabolizing enzymes and histopathological studies," Molecular and Cellular Biochemistry, vol. 287, no. 1-2, pp. 127-135, 2006.

[8] F. I. Abdullaev, "Inhibitory effects of crocetin on intracellular nucleic acid and protein synthesis in malignant cells," Toxicology Letters, vol. 70, no. 2, pp. 243-251, 1994.

[9] E. D. Murphy, "Studies in carcinogen-induced carcinoma of the cervix in mice," American Journal of Pathology, vol. 29, p. 608, 1953.

[10] M. M. Mueller and N. E. Fusenig, "Friends or foes-bipolar effects of the tumour stroma in cancer," Nature Reviews Cancer, vol. 4, no. 11, pp. 839-849, 2004.

[11] A. Hara and I. Okayasu, "Cyclooxygenase-2 and inducible nitric oxide synthase expression in human astrocytic gliomas: correlation with angiogenesis and prognostic significance," Acta Neuropathologica, vol. 108, no. 1, pp. 43-48, 2004.

[12] L. F. Hu, P. T. H. Wong, P. K. Moore, and J. S. Bian, "Hydrogen sulfide attenuates lipopolysaccharide-induced inflammation by inhibition of $\mathrm{p} 38$ mitogen-activated protein kinase in microglia," Journal of Neurochemistry, vol. 100, no. 4, pp. 11211128, 2007.

[13] K. J. Sales, A. A. Katz, B. Howard et al., "Cyclooxygenase-1 is up-regulated in cervical carcinomas: autocrine/paracrine regulation of cyclooxygenase-2, prostaglandin e receptors, and angiogenic factors by cyclooxygenase-1," Cancer Research, vol. 62, pp. 424-432, 2002.

[14] A. D. Santin, F. Zhan, E. Bignotti et al., "Gene expression profiles of primary HPV16- and HPV18-infected early stage cervical cancers and normal cervical epithelium: identification of novel candidate molecular markers for cervical cancer diagnosis and therapy," Virology, vol. 331, no. 2, pp. 269-291, 2005.

[15] S. Tamir and S. R. Tannenbaum, "The role of nitric oxide $\left(\mathrm{NO}^{\circ}\right)$ in the carcinogenic process," Biochimica et Biophysica Acta (BBA)-Reviews on Cancer, vol. 1288, no. 2, pp. F31-F36, 1996.

[16] V. Darley-Usmar, H. Wiseman, and B. Halliwell, "Nitric oxide and oxygen radicals: a question of balance," FEBS Letters, vol. 369, no. 2-3, pp. 131-135, 1995.

[17] S. S. S. Beevi, A. M. H. Rasheed, and A. Geetha, "Evaluation of oxidative stress and nitric oxide levels in patients with oral cavity cancer," Japanese Journal of Clinical Oncology, vol. 34, no. 7, pp. 379-385, 2004.

[18] V. Bhuvarahamurthy, N. Balasubramanian, and S. Govindasamy, "Effect of radiotherapy and chemoradiotherapy on circulating antioxidant system of human uterine cervical carcinoma," Molecular and Cellular Biochemistry, vol. 158, no. 1, pp. 17-23, 1996.
[19] V. Manju, J. K. Sailaja, and N. Nalini, "Circulating lipid peroxidation and antioxidant status in cervical cancer patients: a casecontrol study," Clinical Biochemistry, vol. 35, no. 8, pp. 621-625, 2002.

[20] T. Yamanaka, S. Matsumoto, S. Teramukai, R. Ishiwata, Y. Nagai, and M. Fukushima, "The baseline ratio of neutrophils to lymphocytes is associated with patient prognosis in advanced gastric cancer," Oncology, vol. 73, no. 3-4, pp. 215-220, 2008.

[21] Q. D. I. Wu, J. H. Wang, C. Condron, D. Bouchier-Hayes, and H. P. Redmond, "Human neutrophils facilitate tumor cell transendothelial migration," The American Journal of Physiology: Cell Physiology, vol. 280, no. 4, pp. 814-822, 2001.

[22] D. Widomski, D. J. Fretland, A. F. Gasiecki, and P. W. Collins, "The prostaglandin analogs, misoprostol and SC-46275, potently inhibit cytokine release from activated human monocytes," Immunopharmacology and Immunotoxicology, vol. 19, no. 2, pp. 165-174, 1997.

[23] G. J. del Zoppo, G. W. Schmid-Schönbein, E. Mori, B. R. Copeland, and C.-M. Chang, "Polymorphonuclear leukocytes occlude capillaries following middle cerebral artery occlusion and reperfusion in baboons," Stroke, vol. 22, no. 10, pp. 1276$1283,1991$.

[24] J. K. Kundu and Y.-J. Surh, "Inflammation: gearing the journey to cancer," Mutation Research-Reviews in Mutation Research, vol. 659, no. 1-2, pp. 15-30, 2008.

[25] A. G. Pantschenko, I. Pushkar, K. H. Anderson et al., "The interleukin-1 family of cytokines and receptors in human breast cancer: implications for tumor progression," International Journal of Oncology, vol. 23, pp. 269-284, 2003.

[26] F. Balkwill, "Tumour necrosis factor and cancer," Nature Reviews Cancer, vol. 9, no. 5, pp. 361-371, 2009.

[27] R. M. Clancy, A. R. Amin, and S. B. Abramson, "The role of nitric oxide in inflammation and immunity," Arthritis and Rheumatism, vol. 41, pp. 1141-1151, 1998.

[28] H. Yaren, H. Mollaoglu, B. Kurt et al., "Lung toxicity of nitrogen mustard may be mediated by nitric oxide and peroxynitrite in rats," Research in Veterinary Science, vol. 83, no. 1, pp. 116-122, 2007.

[29] K. Subbaramaiah and A. J. Dannenberg, "Cyclooxygenase 2: a molecular target for cancer prevention and treatment," Trends in Pharmacological Sciences, vol. 24, no. 2, pp. 96-102, 2003.

[30] R. N. DuBois and W. E. Smalley, "Cyclooxygenase, NSAIDs, and colorectal cancer," Journal of Gastroenterology, vol. 31, no. 6, pp. 898-906, 1996. 


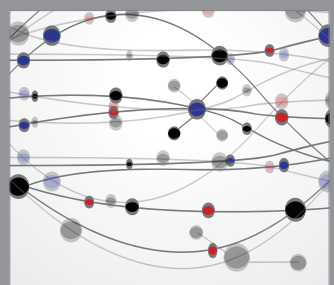

The Scientific World Journal
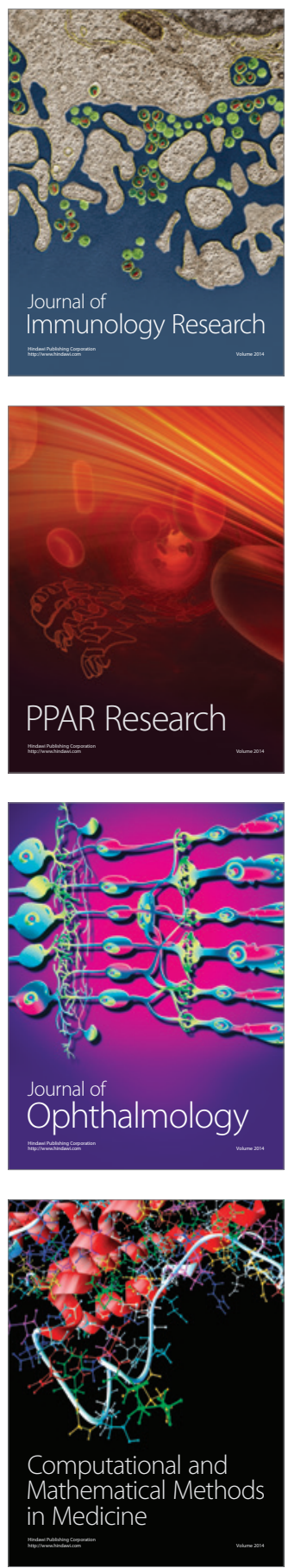

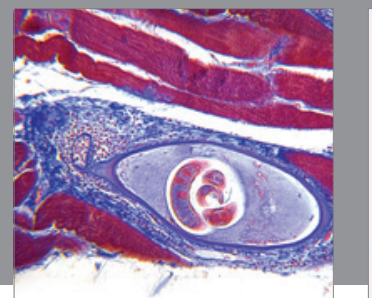

Gastroenterology

Research and Practice
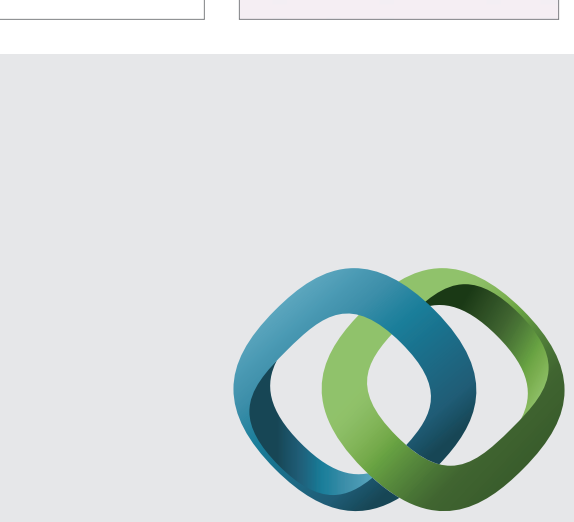

\section{Hindawi}

Submit your manuscripts at

http://www.hindawi.com
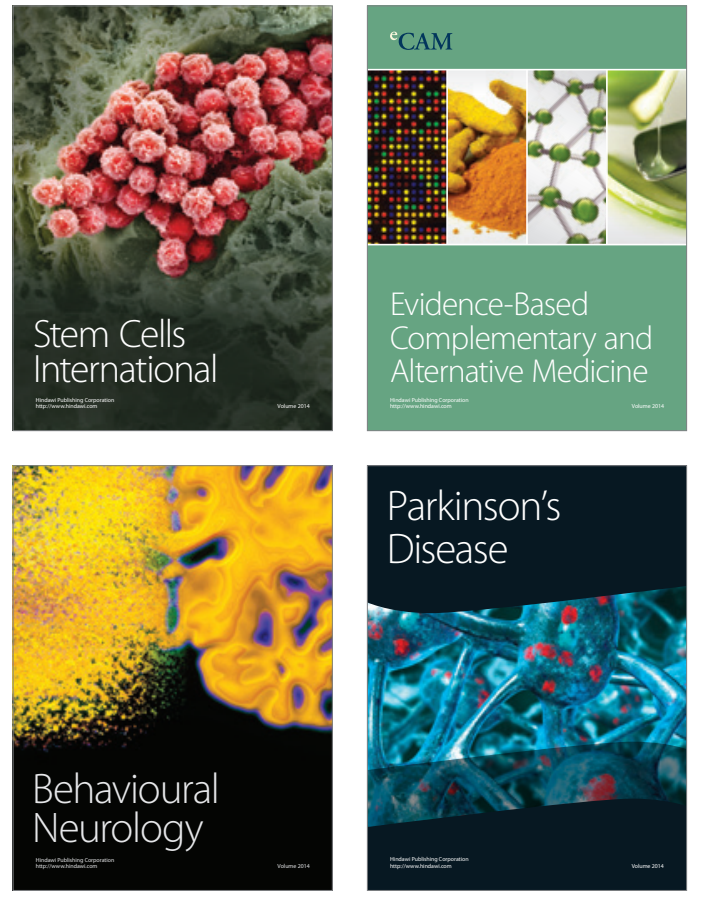
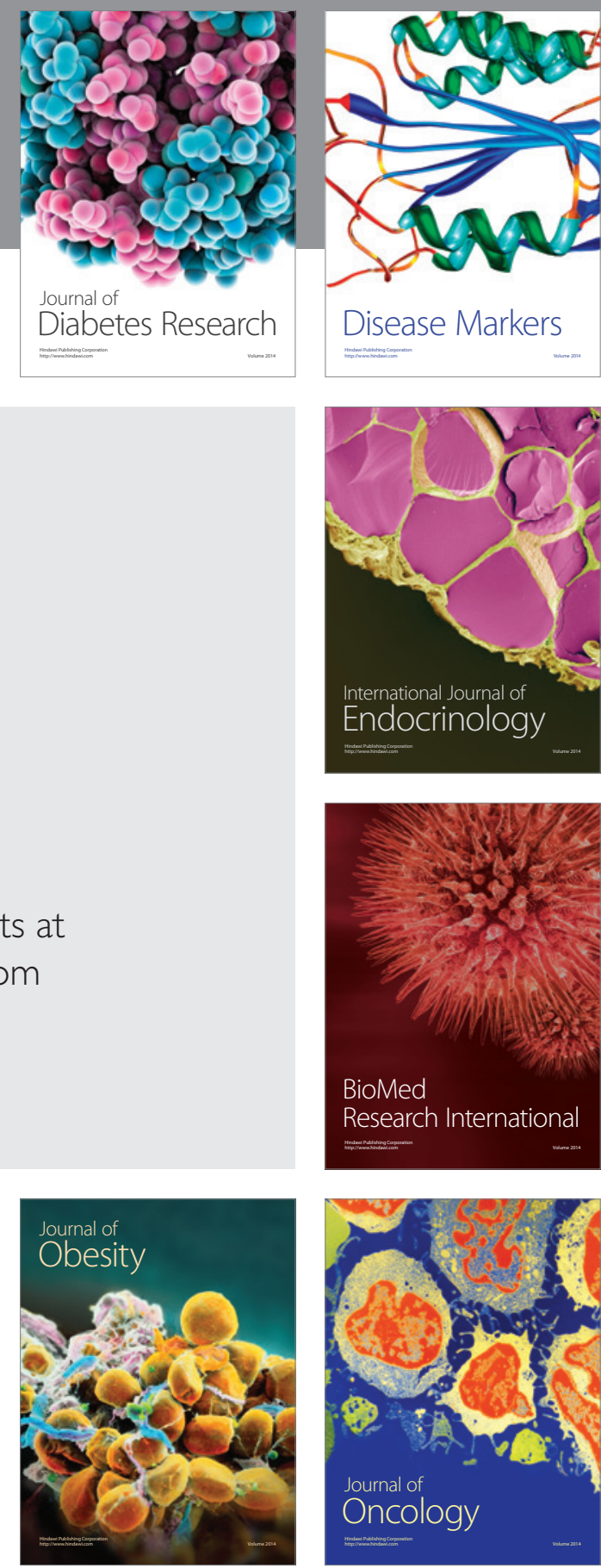

Disease Markers
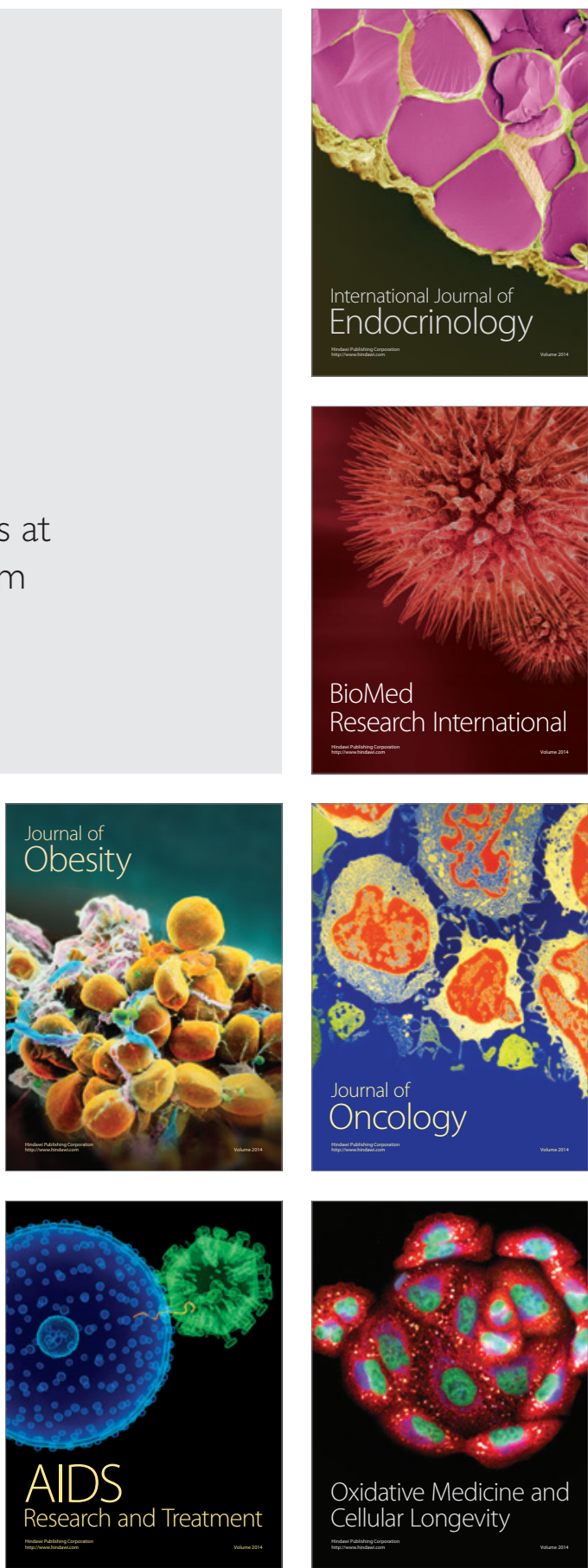